\title{
The interplay of spatial and climatic landscapes in the genetic distribution of a South American parrot
}

\author{
Juan F. Masello ${ }^{1,2 *}$, Valeria Montano ${ }^{3,4}$, Petra Quillfeldt ${ }^{2}$, Soňa \\ Nuhlíčková $^{3}$, Martin Wikelski ${ }^{1}$ and Yoshan Moodley ${ }^{3,5}$
}

\author{
${ }^{1}$ Max Planck Institute for Ornithology, \\ Vogelwarte Radolfzell, Radolfzell, Germany, \\ ${ }^{2}$ Department of Animal Ecology \& \\ Systematics, Justus Liebig University Giessen, \\ Giessen, Germany, ${ }^{3}$ Department of Integrative \\ Biology and Evolution, Konrad Lorenz \\ Institute for Ethology, University of \\ Veterinary Medicine Vienna, Vienna, Austria, \\ ${ }^{4}$ Department of Ecology and Evolution, \\ University of Lausanne, Lausanne, \\ Switzerland, ${ }^{5}$ Department of Zoology, \\ University of Venda, Thohoyandou, South \\ Africa
}

\begin{abstract}
Aim Our aim was to understand the interplay of heterogeneous climatic and spatial landscapes in shaping the distribution of nuclear microsatellite variation in burrowing parrots, Cyanoliseus patagonus. Given the marked phenotypic dif ferences between populations of burrowing parrots we hypothesized an impor tant role of geographical as well climatic heterogeneity in the population structure of this species.
\end{abstract}

Location Southern South America.

Methods We applied a landscape genetics approach to investigate the explicit patterns of genetic spatial autocorrelation based on both geography and climate using spatial principal component analysis (sPCA). This necessitated a novel statistical estimation of the species climatic landscape, considering temperature and precipitation based variables separately to evaluate their weight in shaping the distribution of genetic variation in our model system.

Results Geographical and climatic heterogeneity successfully explained molec ular variance in burrowing parrots. sPCA divided the species distribution into two main areas, Patagonia and the pre Andes, which were connected by an area of geographical and climatic transition. Moreover, sPCA revealed cryptic and conservation relevant genetic structure: the pre Andean populations and the transition localities were each divided into two groups, each management units for conservation.

Main conclusions SPCA, a method originally developed for spatial genetics, allowed us to unravel the genetic structure related to spatial and climatic land scapes and to visualize these patterns in landscape space. These novel climatic inferences underscore the importance of our modified sPCA approach in revealing how climatic variables can drive cryptic patterns of genetic structure, making the approach potentially useful in the study of any species distributed over a climatically heterogeneous landscape.

\section{Keywords}

Argentina, Aves, burrowing parrot, Chile, Cyanoliseus patagonus, climatic landscape, genetic structure, Psittaciformes, spatial landscape, spatial principal component analysis.
Correspondence: Juan F. Masello, Departi of Animal Ecology \& Systematics, Justus Liebig University Giessen, Heinrich Buff Ring 38, D 35392, Giessen, Germany.

E mail: juan.f.masello@bio.uni giessen.de
Cordillera (the Andes itself). Prominent relief is widespread on the eastern side of the Andes (Strecker et al., 2007), where the Cordillera, the Precordillera (pre Andes), and associated sierras (ridges), constitute orographic structures that may impose constraints on the ability of animals to col onize new habitats and thus affect the structure, adaptability and persistence of populations (e.g. Turchetto Zolet et al.,
High biodiversity and complex phylogeographical patterns evolved in South America because of a combination of past orogenic events and climatic cycling (e.g. Iglesias et al., 2011; Sérsic et al., 2011; Tambussi, 2011). The uplift of the Andes generated heterogeneous landscapes on both sides of the 
2013; Fig. 1). Heterogeneous climatic types are also present on both sides of the Andes (Fig. 1), which may also strongly influence species distributions and promote genetic structur ing (e.g. Sork et al., 2010). Understanding how genetic varia tion is influenced by landscape and climate heterogeneity is crucial to better predict how species might cope with climate change and to increase our ability to confront the conse quences of future changes (e.g. Manel et al., 2010). However, despite growing knowledge of the structuring of population level diversity in South America (Turchetto Zolet et al., 2013), the processes involved are largely unknown (Ruzzante \& Rabassa, 2011).

Landscape genetics (Manel et al., 2003) is an analytical framework that incorporates individual population genetic and spatial data for detailed analyses of the landscapes in which those individuals are found (e.g. Manel et al., 2010; Sork \& Waits, 2010). The aim of landscape genetics is to understand how evolutionary processes interact with abiotic changes (e.g. Holderegger \& Wagner, 2006), inclusive of the interplay between climate and geography (e.g. Eckert et al., 2010; Sork et al., 2010; Buckley et al., 2012).

We here focus on a species that may represent a powerful model for the study of genetic responses to climatic and geographical patterns: the burrowing parrot, Cyanoliseus patagonus (Vieillot, 1818). Not only are the locations of all breeding sites across an extensive distribution in southern South America known, but this range is bisected by the southern Central Andes (up to $6900 \mathrm{~m}$ ) and the Patagonian Andes, which constitute a substantial geographical barrier (Fig. 1). Climatic conditions across this region vary consider ably, although arid to semi arid conditions prevail (Fig. 1). In Chile, the species inhabits the 'Matorral', whereas in Argentina, the species is found in the 'Monte', the 'Chaco Seco', the Patagonian steppes and the 'Espinal' ecoregions
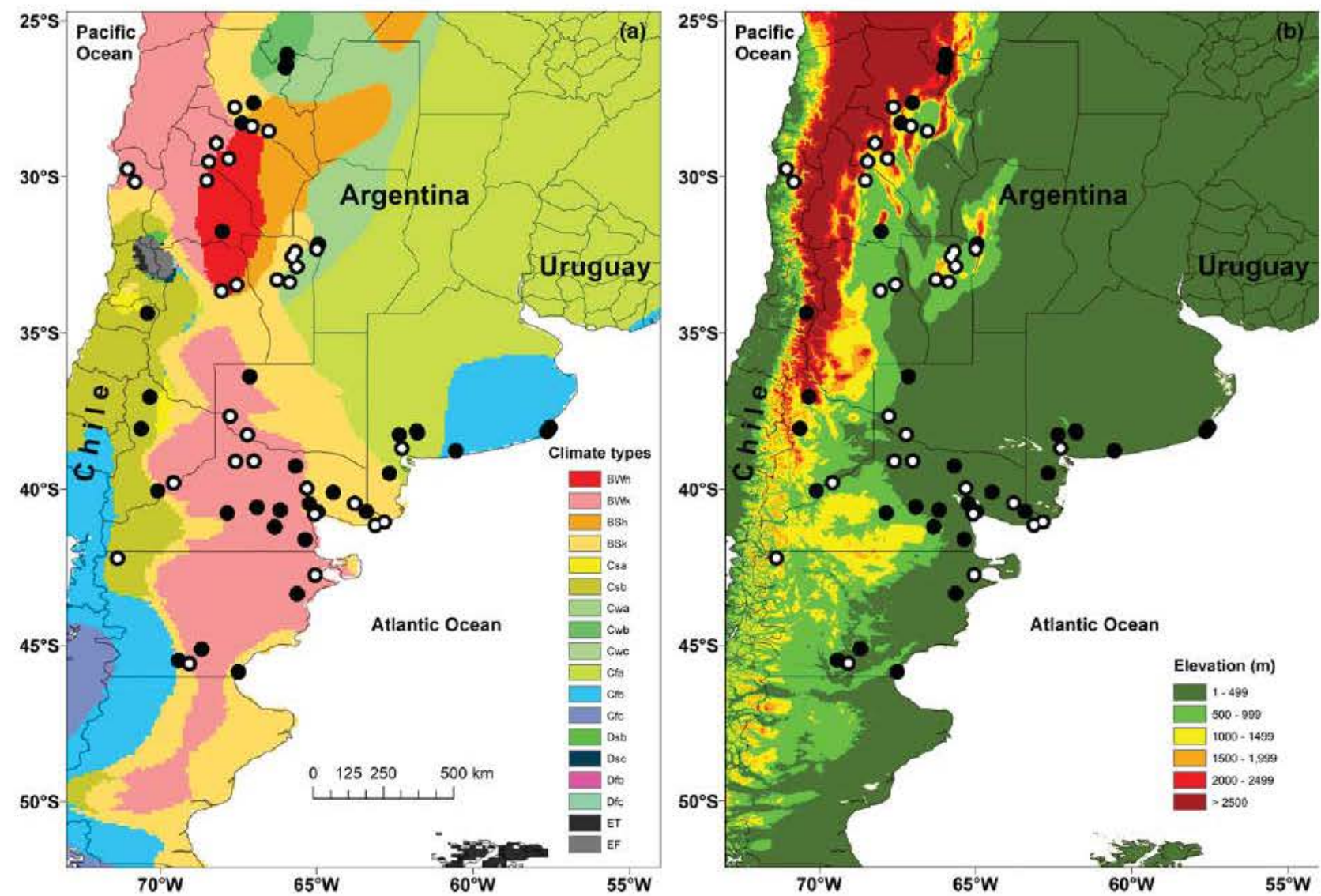

Figure 1 The distribution of colonies and roosts of the burrowing parrot (Cyanoliseus patagonus) in southern South America. The 64 localities with burrowing parrot colonies and roosts included in the climatic analysis are marked with black circles. The 31 localities sampled for the genetic analysis are marked with white circles. Panel (a) shows the diversity of climate types in the region following Kottek et al. (2006) and Peel et al. (2007): arid, desert, hot (BWh); arid, desert, cold (BWk); arid, steppe, hot (BSh); arid, steppe, cold (BSk); temperate, dry summer, hot summer (Csa); temperate, dry summer, warm summer (Csb); temperate, dry winter, hot summer (Cwa); temperate, dry winter, warm summer (Cwb); temperate, dry winter, cold summer (Cwc); temperate, without dry season, hot summer (Cfa); temperate, without dry season, warm summer (Cfb); temperate, without dry season, cold summer (Cfc); cold, dry summer, warm summer (Dsb); cold, dry summer, cold summer (Dsc); cold, without dry season, warm summer (Dfb); cold, without dry season, cold summer (Dfc); polar, tundra (ET); polar, frost (EF). Panel (b) shows the elevation (metres) plotted with DIVA GIs. The data were derived from the Shuttle Radar Topography Mission as described in Reuter et al. (2007). 
(Masello et al., 2011). Formerly, burrowing parrots were common, but they are now only regionally abundant and have disappeared from large parts of their former distribu tional range. The situation is particularly worrying in Chile and in the north west of Argentina, where burrowing parrots have strongly declined (e.g. Rojas Martínez, 2008; Masello et al., 2011).

Masello et al. (2011) traced the evolutionary history of the burrowing parrot using mitochondrial DNA (mtDNA) and found that the species originated in Chile. A single successful migration event across the Andes during the late Pleistocene gave rise to all extant Argentinian mitochondrial lineages. Maternal population structure comprises a single ancestral lineage in Chile (Bloxami), three derived lineages in Argen tina (Andinus, Patagonus1, Patagonus2), and a hybrid zone that has remained stable for several thousand years in the Serranías Centrales (Argentina; Masello et al., 2011). Using multivariate regressions, Masello et al. (2011) also found that up to $48 \%$ of the heterogeneity in the mtDNA data set could be accounted for by present day climatic variables. The cli matic variables associated with genetic variation were mainly temperature related (temperature seasonality, temperature annual range, isothermality), with precipitation seasonality playing only a partial role. This was surprising, given the species' strong dependence on water and tolerance of highly variable temperatures across its range (Masello \& Quillfeldt, 2004). However, in Masello et al. (2011), climatic variables were considered separately, so that their natural correlation (i.e. redundancy) was not taken into account and it was thus not possible to estimate the exact fraction of genetic variance attributable to particular variables.

Given the marked phenotypic differences between popula tions of burrowing parrots (Darrieu, 1980) and the relation ship previously observed between mtDNA heterogeneity and climate, we hypothesized an important role of geographical (latitude plus longitude) and climate heterogeneity in the structuring of burrowing parrot populations. However, as the genetic patterns driven by these abiotic factors may often be cryptic or subtle, they are not always detected via regres sion models. Thus, we applied a landscape genetics approach, spatial principal component analysis (sPCA; Jombart et al., 2008), to investigate the explicit patterns of nuclear microsat ellite spatial autocorrelation in landscape space. Because two dimensional representations of climatic landscapes do not presently exist, we developed a novel PCA based approach to estimate climatic coordinates in landscape space prior to assessing their genetic spatial autocorrelation. Furthermore, we split climatic data into temperature and precipitation based categories in order to evaluate the weight of the differ ent climatic components in shaping the distribution of genetic variation in our model. By avoiding redundancy, we hypothesized a less predominant role for temperature based variables and a more important role for precipitation. Addi tionally, we expected to unravel genetic structure relevant to conservation assessment. Lastly, we aimed to provide the field of landscape genetics with an extended application of
sPCA that may prove to be of broad interest and application in future continental scale studies.

\section{MATERIALS AND METHODS}

\section{Sampling}

A large scale sampling effort covering almost the entire range of the burrowing parrot was carried out in November December 2007 and October November 2008 (Argentina), and in February 2008 (Chile). Feathers were collected non invasively at 26 colonies and five roosts (Fig. 1, and see Appendix S1 in Supporting Information). As most burrow ing parrot colonies have an associated roost, we sampled roosts for several colonies where access was difficult or impossible (e.g. on private property). During the breeding season roosts are used by non breeders and failed breeders (Masello et al., 2006). Detailed observations carried out at El Cóndor (Masello et al., 2006), showed that the birds congre gated first at the colony on their return from feeding areas, and then flew in groups to the roosting place. This suggests that individuals at the roosts should be mostly resident birds. Because burrowing parrots moult their primary feathers at the beginning of their breeding season, from November onwards (Bucher et al., 1987; Masello et al., 2008), sample collection is usually straightforward, as feathers tend to accu mulate at the bottom of colony bearing cliffs. Burrowing parrots can fly up to $66 \mathrm{~km}$ from their colonies during the breeding season and show seasonal movements (Masello et al., 2006), making it possible that individuals move between colonies. However, several ringed nestlings in the El Cóndor (Patagonia) breeding colony returned to the same colony as adults and bred in nests excavated a few metres from the nests in which they were born (Masello \& Quillfeldt, 2012), suggesting a strong degree of philopatry in this species. Thus, although possible, we assumed that fledglings do not frequently move away from their colonies of birth. Furthermore, the sampled feathers were moulted and collected during the breeding season, a time of the year when burrowing parrots do not migrate or move between colonies. We are confident therefore, that the sampled feath ers belong to individuals breeding in the colonies (91\% of all individuals; Masello et al., 2006) where the samples were collected. The two southernmost populations in Chile were not accessible.

\section{Microsatellite genotyping and genetic variation}

DNA was extracted from the feather quill, for a subset of 329 individuals from each of 31 studied colonies using the DNAeasy kit (Qiagen, Hilden, Germany). PCR amplifications were performed for seven species specific tetranucleotide microsatellite loci originally isolated by Klauke et al. (2009). Reactions consisted of a final volume of $10 \mu \mathrm{L}$ including $1 \mu \mathrm{L} 10 \times$ QIAGEN PCR buffer (TrisCl, $\mathrm{KCl}$ and $\left(\mathrm{NH}_{4}\right)_{2} \mathrm{SO}_{4}$ at unspecified concentrations), $0.5 \mu \mathrm{L}$ of each of 
$10 \mu \mathrm{M}$ forward and reverse primers, $1.5 \mathrm{~mm} \mathrm{MgCl}_{2}, 0.40 \mathrm{~mm}$ of each dNTP and $0.5 \mathrm{U}$ Taq DNA polymerase (Qiagen) and $1 \mu \mathrm{L}$ template, using an Eppendorf Mastercycler Gradient (Eppendorf, Wesseling Berzdorf, Germany). A touchdown thermal cycling programme encompassing a $10{ }^{\circ} \mathrm{C}$ span of annealing temperatures ranging between 60 and $50{ }^{\circ} \mathrm{C}$ was used for the amplification. Following an initial denaturation step of $95{ }^{\circ} \mathrm{C}$ for $3 \mathrm{~min}$, the cycling parameters were: 20 cycles at $95{ }^{\circ} \mathrm{C}$ for $30 \mathrm{~s}$, an annealing temperature of $60{ }^{\circ} \mathrm{C}$ (decreasing by $0.5{ }^{\circ} \mathrm{C}$ per cycle) for $30 \mathrm{~s}, 72{ }^{\circ} \mathrm{C}$ for $40 \mathrm{~s}, 15$ cycles of $95{ }^{\circ} \mathrm{C}$ for $30 \mathrm{~s}, 50{ }^{\circ} \mathrm{C}$ for $30 \mathrm{~s}, 72{ }^{\circ} \mathrm{C}$ for $40 \mathrm{~s}$, and a final extension step of $72{ }^{\circ} \mathrm{C}$ for $5 \mathrm{~min}$. PCR products were run on Elchrom Spreadex EL 400 gels in an Elchrom SEA 2000 apparatus and sized with the M3 size standard (Elchrom, Cham, Switzerland).

Although we cannot exclude a degree of relatedness among individuals sampled at each site, there were no identical genotypes within the dataset (Appendix S1). We calculated indices of multilocus genetic diversity (number of alleles per locus, number of alleles per population, expected and observed heterozygosity) using the $\mathrm{R}$ package ADEGENET (Jombart, 2008), and deviations from Hardy Weinberg equi librium (HWE) by testing for heterozygote deficiency and heterozygote excess using Fstat 2.9.3 (Goudet, 1995).

\section{Power of prediction: climate, geography and genetics}

To disentangle the relationship between climate and geography (here and throughout the text: latitude plus longitude), we used 21 interpolated climatic variables (Appendix S1) based on the WorldClim database version 1.3 (http://www.worldclim.org) at 2.5 minutes resolution (Hijmans et al., 2005) from 64 burrowing parrot colonies and roosts, using DIVA GIS (http://www.diva gis.org). As in the case of other interpolated databases, a certain degree of uncertainty arises from areas with low density of weather sta tions, elevation bias in the weather stations, and/or elevation variation within grid cells. Thus, uncertainty is highest in mountainous areas where interpolation does not capture all the variation that may occur at $\leq 1 \mathrm{~km}$, particularly for pre cipitation (Hijmans et al., 2005). Although the interpolations in some of the areas studied here are based on a relatively low density of weather stations (see maps in Hijmans et al., 2005), distances between two colonies where mostly well above $50 \mathrm{~km}$ and in no case below $8 \mathrm{~km}$. Consequently, we assumed that WorldClim captures most of the climatic variation occurring among the studied colonies.

The WorldClim climatic parameters comprised two main categories: 13 temperature based $\left({ }^{\circ} \mathrm{C}\right)$ variables, and eight precipitation based (millimetres) variables. Because climatic parameters are expected to co vary with geography, we esti mated a correlation matrix among geographical coordinates and climatic variables (Appendix S1) using the BASE PACK AGE in R ( $\mathrm{R}$ Core Team, 2013). To investigate this relation ship more thoroughly, we used two multivariate analyses: redundancy analysis (RDA; van den Wollenberg, 1977) and canonical correspondence analysis (CCA; Ter Braak, 1986), both of which were implemented in the $\mathrm{R}$ package VEGAN (Oksanen et al., 2012). The analyses assume linear (RDA) and Gaussian (CCA) relationships among response (climate) and predictor (geography) variables respectively. A Gaussian transformation may better approximate the true distribution describing the relationship between variables when a straight forward linear relationship is not supported. The power of prediction of latitude and longitude, separately and jointly, was tested both on the complete climatic data set and on separate temperature and precipitation subsets. We also con sidered elevation as a third geographical variable, but a regression model showed that, while latitude and longitude were statistically, and intuitively, uncorrelated $\left(\begin{array}{rr}r^{2} & 0.010\end{array}\right)$, elevation was highly predicted by latitude and to a lesser extent by longitude $\left(r^{2} \quad 0.629\right.$ and $r^{2} \quad 0.201$, respectively, $P<0.001)$. Given this redundancy we excluded elevation from the following analyses. We then extended this frame work to include multilocus population allele frequencies as the response variable, thus testing the marginal and condi tional power of geography and climate in predicting the dis tribution of genetic heterogeneity.

\section{Spatial principal component analysis for geographical and climatic landscapes}

We investigated the spatial autocorrelation of our genetic data to spatial and climatic landscapes of burrowing parrot localities by applying sPCA. This method undertakes an explicit synthesis of the organization of the genetic variance among sampling locations and its correlation to distances among locations (Jombart et al., 2008), using information obtained from principal component analysis and a spatial autocorrelation index (Moran's index; Moran, 1950).

We defined connection networks for geographical and cli matic data sets. These are matrices of spatial weights, required to calculate the spatial autocorrelation (Moran, 1950). We calculated these as matrices of inverse distances connecting all 31 sampling locations, because this is less arbi trary than binary Gabriel graphs, where user defined neigh bours are denoted 1, and non neighbours 0 . As sPCA is two dimensional, connection networks were constructed from pairs of coordinates from each sampling locality. This was straightforward for the geographical data set, because we were able to code each locality using latitude and longitude. In order to define sampling localities on the basis of their climatic affinities, we employed a novel method involving principal components analyses. Based on results obtained from the correlation and multivariate analyses above, we kept temperature and precipitation data sets separate, per forming a separate PCA on each. Both temperature and pre cipitation correlation matrices were significantly spherical (Bartlett's test of sphericity, $\chi^{2} \quad 559.9$, d.f. $\quad 78, P<0.001$; $\chi^{2} \quad 1925.4$, d.f. $28, P<0.001$ ), while the Kaiser Meyer Olkin measure of sampling adequacy reached the required 
level of 0.5 in both cases. We were then able to use the PC loading scores along pairs of those components that cumula tively described $99.9 \%$ of the variation in the temperature and precipitation data as climatic 'coordinates' to produce connection networks that summarized the climatic landscape across the species range. Finally, sPCA was performed on all geographical and climatic connection networks. The resulting positive eigenvectors account for global spatial structure such as large gradients or patches (positive spatial autocorrela tion), whereas negative eigenvectors retrieve information on local spatial structure which may result from negative mating between adjacent locations (negative spatial autocorrelation). A Monte Carlo simulation (global and local tests; global.rtest and local.rtest in the ADEGENET package) was used to test for non random association of population allele frequencies with geographical and climatic landscapes. Given a significant glo bal or local test, the most positive and negative eigenvalues encompass the most important synthesis of geographical/cli matic to genetic information. sPCA scores for each location were mapped against connection networks for globally or locally significant component pairs.

\section{RESULTS}

\section{Genetic variation}

The number of alleles per locus ranged between 8 and 12 and the differences between observed and expected hetero zygosities did not suggest deviation from $\operatorname{HWE}\left(\chi^{2} \quad 0.999\right.$, $P \quad 0.230$; Tables $1 \& 2$ ). Tests of heterozygote deficiency or excess were carried out for all populations with more than two individuals and $P$ values were adjusted for multiple comparisons (Bonferroni correction). Only one population, Guardia Mitre (Table 2), showed significant multilocus het erozygote deficiency at the 0.05 level. Despite this, we found that this population did not behave any differently to those to which it was adjacent after downstream analyses. Although variable numbers of individuals were sampled per population (Table 2), all landscape analyses were carried out using aver age allele frequencies per locus per locality to avoid the redundancy of climatic and geographical variables.

Table 1 Genetic variation at each of seven microsatellite loci across 31 populations of the burrowing parrot (Cyanoliseus patagonus) that were sampled in southern South America for genetic analysis.

\begin{tabular}{llrll}
\hline Locus & GenBank no. & $A$ & $H_{\mathrm{O}}$ & $H_{\mathrm{E}}$ \\
\hline Cyanp 1 & EU732667 & 10 & 0.77 & 0.81 \\
Cyanp 2 & EU732668 & 8 & 0.34 & 0.41 \\
Cyanp 3 & EU732669 & 12 & 0.69 & 0.73 \\
Cyanp 4 & EU732670 & 13 & 0.78 & 0.83 \\
Cyanp 5 & EU732671 & 13 & 0.7 & 0.77 \\
Cyanp 6 & EU732672 & 13 & 0.74 & 0.81 \\
Cyanp 7 & EU732673 & 9 & 0.39 & 0.79 \\
\hline
\end{tabular}

$A$, number of alleles per locus; $H_{\mathrm{O}}$, observed heterozygosity; $H_{\mathrm{E}}$, expected heterozygosity. See also Fig. 1 and Appendix S1.

\section{Predicting power of climate and genetics}

From our matrix of correlations, we found that the 21 climatic variables conformed to two highly correlated tem perature and precipitation based clusters (see Fig. S1 in Appendix S1). Using a multivariate approach, we showed that geography was able to predict climate (temperature plus precipitation) significantly $(P<0.05)$ assuming both linear and Gaussian correlations (Table 3 ). When investigat ing the relationship between geography and temperature/ precipitation variables separately, a significant linear rela tionship was found for geographical coordinates in explain ing precipitation based climatic variables, while geography predicted temperature based climatic variables significantly only when a Gaussian relationship was assumed (Table 3). When geography was broken down into latitude and longi tude, we found that both were able to explain a significant proportion of the variance among temperature variables under a Gaussian relationship (CCA, $P \quad 0.005$ in both cases), whereas latitude showed a significant linear relation ship with precipitation variables (RDA, $P$ 0.005), while longitude showed a significant nonlinear correlation (CCA, $P$ 0.005).

When the distribution of allele frequencies was consid ered as the response variable, we found that more tests were significant $(P<0.05)$ when variables were assumed to be linear distributed rather than Gaussian distributed (Table 4). Under the linear assumption of the multivariate RDA, significant $(P<0.05)$ marginal variation was explained by geography, but not by climate, despite a large proportion of explainable molecular variance owing to cli mate $(82 \%)$, and geography plus climate together (85\%). No regressions were significant when the marginal variation explained by either one of these variable sets (geography or climate) was made conditional on the other (Table 4). However, when climate was broken up into its two compo nent variable sets, both temperature and precipitation sig nificantly explained molecular variance when considered both singularly and together with geography (Table 4). Nevertheless, only temperature was still significant when the marginal variance it explained was conditional on geogra phy (RDA and CCA analyses) and geography was not sig nificant when made conditional on either temperature or precipitation (Table 4). Therefore, despite significant corre lations between geographical and climatic subsets (Table 3), their interrelationship in predicting genetic variation (Table 4) was not straightforward. Despite this, even after subtracting conditional variation owing to geography, $46 \%$ and $34 \%$ (RDA) of the variation in the molecular data set could still be explained by temperature and precipitation, respectively.

\section{Climatic landscape}

Prior to landscape analysis, we conducted a PCA for each of the two climatic subsets (13 temperature and eight 
precipitation based variables), in order to convert the het erogeneity among climatic variables into climatic 'coordi nates' from which two dimensional connection networks could be constructed and sPCA performed. We found that the first two temperature principal components (TPC 1 and TPC 2) accounted for almost all (99.4\%) of the vari ance, with the variable temperature seasonality contributing almost solely to the first component (Table 5). The first two precipitation principal components (PPC 1 and PPC

2) summarized $94.7 \%$ of the total variance (Table 6), with the remaining variation distributed in three further com ponents. Annual precipitation was the main contributor to PPC 1, while precipitation of the coldest quarter and pre cipitation of the warmest quarter contributed alike to PPC 2 (Table 6).

\section{Landscape genetics}

We constructed connection networks of geographical and cli matic spatial weights using the geographical coordinates (lat itude/longitude; Fig. 2) and climatic coordinates (Figs S2 S5 in Appendix S2). Climatic coordinates were derived from PC loading scores of those pairs of components that account for $99.9 \%$ of the variation in temperature (TPC 14 in Table 5) and precipitation (PPC 15 in Table 6). Significant global (positive) spatial structure was found within the geographical connection network ( $P$ 0.01; Fig. 2). We also tested con nection networks of elevation against latitude and longitude, respectively, but these were non significant.

Geographically, the most positive genetic sPCA eigenvalues showed that the species is also genetically divided into

Table 2 Multilocus genetic variation in the burrowing parrot (Cyanoliseus patagonus) at 31 localities in southern South America that were sampled for genetic analysis.

\begin{tabular}{|c|c|c|c|c|c|}
\hline Locality & Phenotype & mtDNA haplogroup & $n$ & $A$ & $H_{\mathrm{O}}$ \\
\hline \multicolumn{6}{|l|}{ PAMPAS } \\
\hline Bahía Blanca (1) & C. p. patagonus & Patagonus1 & 28 & 41 & 0.642 \\
\hline \multicolumn{6}{|l|}{ PATAGONIA } \\
\hline La Mina river (3) & C. p. patagonus & Patagonus1 & 3 & 19 & 0.5 \\
\hline Puerto Madryn (4) & C. p. patagonus & Patagonus1, Patagonus2 & 5 & 28 & 0.657 \\
\hline Sarmiento (5) & C. p. patagonus & N/A & 2 & 13 & 0.339 \\
\hline Colorado river (7) & C. p. patagonus & Patagonus1, Patagonus2 & 33 & 48 & 0.729 \\
\hline Bajada Colorada (15) & C. p. patagonus & Patagonus1, Patagonus2 & 24 & 40 & 0.680 \\
\hline Casa de Piedra (16) & C. p. patagonus & Patagonus1, Patagonus2 & 12 & 37 & 0.664 \\
\hline El Cóndor (17) & C. p. patagonus & Patagonus1, Patagonus2 & 9 & 32 & 0.633 \\
\hline El Solito (18) & C. p. patagonus & Patagonus1, Patagonus2 & 16 & 38 & 0.701 \\
\hline La Lobería (19) & C. p. patagonus & Patagonus1 & 12 & 39 & 0.638 \\
\hline Las Grutas (20) & C. p. patagonus & Patagonus1, Patagonus2 & 12 & 33 & 0.647 \\
\hline Paso Córdoba (21) & C. p. patagonus & Patagonus1, Patagonus2 & 8 & 26 & 0.591 \\
\hline Guardia Mitre (22) & C. p. patagonus & Patagonus1, Patagonus2 & 18 & 39 & 0.663 \\
\hline Villa Regina (23) & C. p. patagonus & Patagonus1, Patagonus2 & 4 & 25 & 0.585 \\
\hline \multicolumn{6}{|l|}{ CUYO (LOWLANDS) } \\
\hline La Paz (13) & C. p. patagonus & N/A & 1 & 13 & 0.428 \\
\hline Pichi Ciego (14) & C. p. andinus & Andinus & 1 & 11 & 0.285 \\
\hline \multicolumn{6}{|l|}{ SERRANÍAS CENTRALES } \\
\hline Piedras Blancas stream (6) & C. p. conlara & Andinus & 1 & 9 & 0.142 \\
\hline Las Chacras (25) & C. p. conlara & Andinus, Patagonus2 & 2 & 18 & 0.535 \\
\hline Paso Grande (26) & C. p. conlara & Andinus, Patagonus2 & 2 & 18 & 0.553 \\
\hline Quinto river (27) & Undetermined & Patagonus2 & 2 & 17 & 0.5 \\
\hline San Luis (28) & Undetermined & Andinus, Patagonus2 & 2 & 23 & 0.642 \\
\hline San Martín stream (29) & C. p. conlara & Andinus, Patagonus1, Patagonus 2 & 2 & 21 & 0.589 \\
\hline \multicolumn{6}{|l|}{ PRE ANDES } \\
\hline Los Morteros, Abaucán river (2) & C. p. andinus & Andinus & 2 & 18 & 0.482 \\
\hline Affluent, Vinchina river (8) & C. p. andinus & Andinus, Patagonus1 & 2 & 20 & 0.589 \\
\hline La Manga (9) & C. p. andinus & N/A & 1 & 10 & 0.214 \\
\hline Los Tambillos (10) & C. p. andinus & Andinus & 1 & 23 & 0.473 \\
\hline San Blas (11) & C. p. andinus & Andinus & 1 & 22 & 0.459 \\
\hline Zanja de la viuda (12) & C. p. andinus & Andinus & 1 & 20 & 0.472 \\
\hline Huaco (24) & C. p. andinus & Andinus & 2 & 18 & 0.553 \\
\hline \multicolumn{6}{|l|}{ CHILEAN MATORRAL } \\
\hline Quebrada de San Carlos (30) & C. p. bloxami & Bloxami & 8 & 27 & 0.620 \\
\hline Santa Gracia (31) & C. p. bloxami & Bloxami & 2 & 14 & 0.428 \\
\hline
\end{tabular}

The landscape where the colonies are located is indicated in bold capitals. Colony numbers as in Fig. 2 and Appendix S1 are given in brackets. Phenotypes according to Darrieu (1980) and Nores \& Yzurieta (1983), mtDNA haplogroup according to Masello et al. (2011). A, number of alleles per locus; $H_{\mathrm{O}}$, observed heterozygosity; N/A, data not available. 
Table 3 Multivariate analyses of the predictability of climate with geography among 64 populations of the burrowing parrot (Cyanoliseus patagonus) from southern South America.

\begin{tabular}{|c|c|c|c|c|}
\hline \multicolumn{2}{|c|}{$\begin{array}{l}\text { Variables in multivariate } \\
\text { regression }\end{array}$} & \multicolumn{2}{|l|}{ Inertia } & \multirow[b]{2}{*}{$P$} \\
\hline Predictor & Response & Absolute & Proportion & \\
\hline \multicolumn{5}{|c|}{ RDA (linear distribution of variables) } \\
\hline Geography & Climate & 19329 & 0.230 & 0.005 \\
\hline Geography & Temperature & 154.7 & 0.032 & 0.35 \\
\hline Geography & Precipitation & 19175 & 0.243 & 0.005 \\
\hline \multicolumn{5}{|c|}{ CCA (Gaussian distribution of variables) } \\
\hline Geography & Climate & 0.115 & 0.629 & 0.005 \\
\hline Geography & Temperature & 0.009 & 0.555 & 0.005 \\
\hline Geography & Precipitation & 0.070 & 0.401 & 0.005 \\
\hline
\end{tabular}

RDA, redundancy analysis; CCA, canonical correspondence analysis. Statistically significant $P$ values are marked in bold.

Patagonian (black squares) and pre Andean (white squares) components, with eight intervening localities, also appearing genetically intermediate $(6,13,14,25,26,27,28$ and 29; lowlands of Cuyo and Serranías Centrales; Fig. 2c, Table 2, Appendix S2). The colony in the Pampas (31) was not differentiated from Patagonian localities. Further genetic structure is revealed when the second positive sPCA eigen value was plotted (Fig. 2d). The pre Andean populations and the eight transition localities were each divided into two groups (black squares and white squares in Fig. 2d; for fur ther details of the distribution of these colonies see Fig. 3).

The only significant temperature based connection net work separated the Chilean populations $(30,31)$ from all others along a gradient of temperature seasonality (TPC 1; Table 5, Fig. S2). This gradient also separated the geographi cally isolated colony of La Mina River (3) from all other Ar gentinian populations, but did not completely separate pre Andean from Patagonian regions (Fig. S2a). Nevertheless genetic variation appeared to link pre Andean populations in Chile and Argentina, despite their separation on either side of TPC 1 (Fig. S2b).

Three of the connection networks combining precipitation principal coordinates PPC 2, PPC 3, PPC 4 and PPC 5 were significant (Figs S3a, S4a \& S5a). All three combinations sep arated Patagonian from pre Andean regions (Figs S3a, S4a \& S5a), while only PPC 3, PPC 4 and PPC 5 separated popula tions on either side of the Andes in Chile and Argentina (Figs S4a \& S5a). Six of the eight populations identified as geographically intermediate $(6,25,26,27,28,29$; Fig. 2) were separated along PPC2 and PPC4 (Fig. S3a \& S4a), but

Table 4 Multivariate analyses of the predictability of genetics with both climate and geography among 64 populations of the burrowing parrot (Cyanoliseus patagonus) from southern South America.

\begin{tabular}{|c|c|c|c|c|c|}
\hline \multicolumn{3}{|c|}{ Variables in multivariate regression } & \multicolumn{2}{|l|}{ Inertia } & \multirow[b]{2}{*}{$P$} \\
\hline Predictor(s) & Conditional & Response & Absolute & Proportion & \\
\hline \multicolumn{6}{|c|}{ RDA (linear distribution of variables) } \\
\hline Geography + Climate & & Genetic & 607.3 & 0.849 & 0.100 \\
\hline Climate & & Genetic & 589.3 & 0.824 & 0.051 \\
\hline Geography & & Genetic & 183.8 & 0.257 & 0.005 \\
\hline Climate & Geography & Genetic & 432.5 & 0.605 & 0.290 \\
\hline Geography & Climate & Genetic & 18.0 & 0.025 & 0.580 \\
\hline Temperature & & Genetic & 488.6 & 0.683 & 0.005 \\
\hline Temperature & Geography & Genetic & 326.0 & 0.456 & 0.050 \\
\hline Precipitation & & Genetic & 389.0 & 0.544 & 0.016 \\
\hline Precipitation & Geography & Genetic & 241.0 & 0.337 & 0.075 \\
\hline Geography + Temperature & & Genetic & 509.8 & 0.713 & 0.020 \\
\hline Geography + Precipitation & & Genetic & 424.8 & 0.594 & 0.023 \\
\hline Geography & Temperature & Genetic & 21.2 & 0.029 & 0.450 \\
\hline Geography & Precipitation & Genetic & 26.8 & 0.037 & 0.400 \\
\hline \multicolumn{6}{|c|}{ CCA (Gaussian distribution of variables) } \\
\hline Geography + Climate & & Genetic & 0.9708 & 0.7495 & 0.16 \\
\hline Climate & & Genetic & 0.8887 & 0.6861 & 0.16 \\
\hline Geography & & Genetic & 0.1415 & 0.1092 & 0.005 \\
\hline Climate & Geography & Genetic & 0.8294 & 0.6403 & 0.17 \\
\hline Geography & Climate & Genetic & 0.0658 & 0.0508 & 0.44 \\
\hline Temperature & & Genetic & 0.6324 & 0.4882 & 0.005 \\
\hline Temperature & Geography & Genetic & 0.5567 & 0.4298 & 0.015 \\
\hline Precipitation & & Genetic & 0.3763 & 0.2905 & 0.19 \\
\hline Precipitation & Geography & Genetic & 0.3109 & 0.2400 & 0.43 \\
\hline Geography + Temperature & & Genetic & 0.7254 & 0.5600 & 0.02 \\
\hline Geography + Precipitation & & Genetic & 0.4523 & 0.3492 & 0.3 \\
\hline Geography & Temperature & Genetic & 0.0658 & 0.0508 & 0.35 \\
\hline Geography & Precipitation & Genetic & 0.07607 & 0.05873 & 0.42 \\
\hline
\end{tabular}

RDA, redundancy analysis; CCA, canonical correspondence analysis. Statistically significant $P$ values are marked in bold. 
Table 5 Results of principal components analysis (PCA) of 13 temperature based climatic variables for 64 populations of the burrowing parrot (Cyanoliseus patagonus) from southern South America.

\begin{tabular}{|c|c|c|c|c|c|}
\hline & \multicolumn{5}{|c|}{ Temperature principal component (TPC) } \\
\hline & 1 & 2 & 3 & 4 & 5 \\
\hline \multicolumn{6}{|l|}{ Variance explained by temperature variables: } \\
\hline Standard deviation & 68.645 & 8.062 & 3.915 & 3.420 & 1.663 \\
\hline Proportion of variance & 0.980 & 0.014 & 0.003 & 0.002 & 0.000 \\
\hline Cumulative proportion & 0.980 & 0.994 & 0.997 & 0.999 & 0.999 \\
\hline Contribution of each temperature variable: & \multicolumn{5}{|c|}{ Loading scores } \\
\hline Mean monthly minimum temperature $\left({ }^{\circ} \mathrm{C}\right)$ & & -0.241 & 0.144 & 0.258 & 0.224 \\
\hline Mean monthly maximum temperature $\left({ }^{\circ} \mathrm{C}\right)$ & & -0.292 & -0.199 & 0.117 & 0.205 \\
\hline Annual mean temperature $\left({ }^{\circ} \mathrm{C}\right)$ & & -0.266 & & 0.189 & \\
\hline Mean monthly temperature range & & & -0.343 & -0.142 & 0.213 \\
\hline Isothermality $(2 / 7)(\times 100)$ & & & -0.703 & -0.253 & \\
\hline Temperature seasonality $($ STD $\times 100)$ & -0.996 & & & & 0.277 \\
\hline Maximum temperature of the warmest month $\left({ }^{\circ} \mathrm{C}\right)$ & & -0.230 & & 0.111 & 0.264 \\
\hline Minimum temperature of the coldest month $\left({ }^{\circ} \mathrm{C}\right)$ & & -0.133 & 0.222 & 0.261 & \\
\hline Temperature annual range & & & -0.312 & -0.150 & -0.618 \\
\hline Mean temperature of the wettest quarter $\left({ }^{\circ} \mathrm{C}\right)$ & & -0.732 & & -0.207 & -0.460 \\
\hline Mean temperature of the driest quarter $\left({ }^{\circ} \mathrm{C}\right)$ & & 0.161 & -0.411 & 0.767 & 0.201 \\
\hline Mean temperature of the warmest quarter $\left({ }^{\circ} \mathrm{C}\right)$ & & -0.259 & & 0.178 & 0.221 \\
\hline Mean temperature of the coldest quarter $\left({ }^{\circ} \mathrm{C}\right)$ & & -0.264 & & 0.183 & \\
\hline
\end{tabular}

Note: the scores of the variables that cumulatively contribute to $99 \%$ of the variance of each PC are reported. The main contributor to each prin cipal component is marked bold. Temperature seasonality: the standard deviation of the weekly mean temperatures expressed as a percentage of the mean of those temperatures (i.e. the annual mean). Isothermality: the mean diurnal range divided by the annual temperature range.

Table 6 Results of principal components analysis (PCA) of eight precipitation based climatic variables of 64 populations of the burrowing parrot (Cyanoliseus patagonus) from southern South America.

\begin{tabular}{|c|c|c|c|c|c|}
\hline & \multicolumn{5}{|c|}{ Precipitation principal component (PPC) } \\
\hline & 1 & 2 & 3 & 4 & 5 \\
\hline \multicolumn{6}{|l|}{ Variance explained by precipitation variables: } \\
\hline Standard deviation & 256.39 & 89.178 & 60.262 & 18.169 & 9.536 \\
\hline Proportion of variance & 0.845 & 0.102 & 0.046 & 0.004 & 0.001 \\
\hline Cumulative proportion & 0.845 & 0.947 & 0.994 & 0.998 & 0.999 \\
\hline Contribution of each precipitation variable: & \multicolumn{5}{|c|}{ Loading scores } \\
\hline Annual precipitation & 0.867 & & -0.292 & & 0.375 \\
\hline Precipitation of the wettest month (mm) & 0.134 & & 0.207 & & 0.107 \\
\hline Precipitation of the driest month $(\mathrm{mm})$ & & & -0.119 & 0.130 & -0.242 \\
\hline Precipitation seasonality $(\mathrm{CV})$ & & & 0.523 & 0.809 & 0.242 \\
\hline Precipitation of the wettest quarter $(\mathrm{mm})$ & 0.359 & & 0.609 & -0.353 & -0.218 \\
\hline Precipitation of the driest quarter $(\mathrm{mm})$ & & & -0.426 & 0.418 & -0.437 \\
\hline Precipitation of the warmest quarter $(\mathrm{mm})$ & 0.227 & 0.695 & 0.110 & & -0.537 \\
\hline Precipitation of the coldest quarter $(\mathrm{mm})$ & 0.205 & -0.713 & 0.138 & 0.126 & -0.452 \\
\hline
\end{tabular}

Note: the scores of the variables that cumulatively contribute to $99 \%$ of the variance of each PC are reported. The main contributor to each prin cipal component is marked bold. Precipitation Seasonality: the standard deviation of the weekly precipitation estimates expressed as a percentage of the mean of those estimates (i.e. the annual mean).

always grouped among the pre Andean localities (see Fig. S3a \& S4a and particularly Fig. S5). This pre Andean link to the geographically intermediate populations was further supported once genetic scores were added to the precipita tion based connection networks (Figs S3c e, S4c e \& S5c e) showing their genetic homogeneity (size and colour of squares) with pre Andean localities. Yet, the two Cuyan colonies identified as geographically closest to Patagonia (13,
14; Fig. 2) remained intermediately positioned along PPC 3 between pre Andean and Patagonian colonies (Figs S3a, S4a \& S5a). Two other colonies $(5,15)$ located well within Pata gonia were also intermediately positioned along PPC 3, although unlike the geographically intermediate colonies 13 and 14, their genetic affinities were always Patagonian (Figs S3c, S4c \& S5c). Lastly, Andean colonies located higher than $1000 \mathrm{~m}$ in elevation $(2,8,12,24)$ were tightly grouped along 


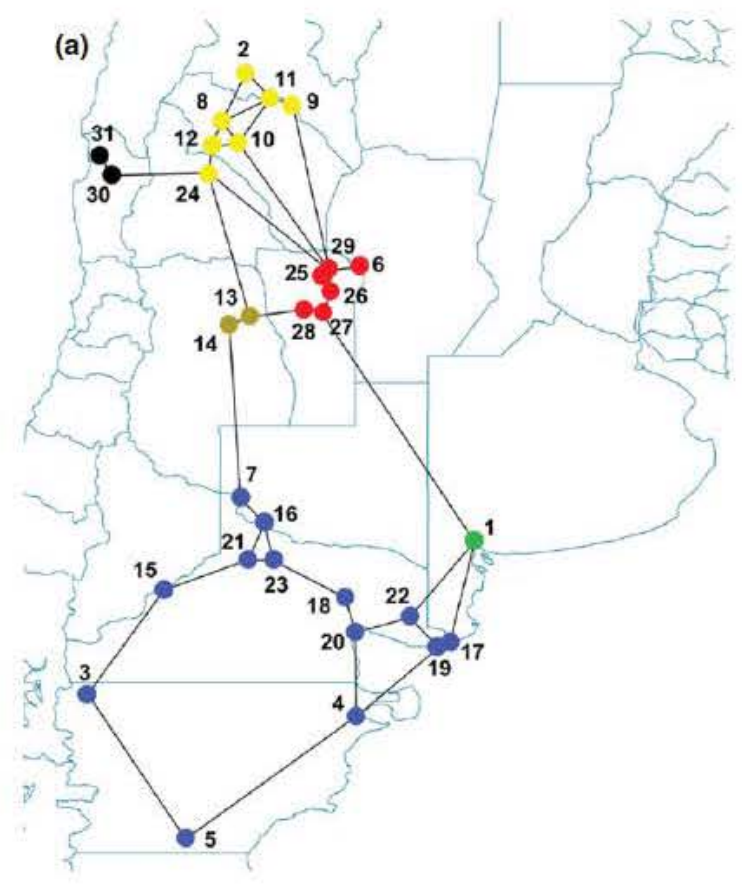

(b)

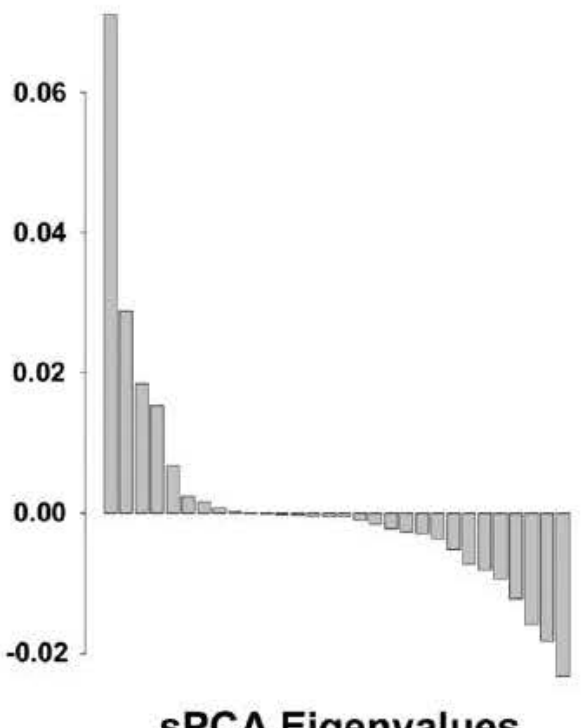

(c)
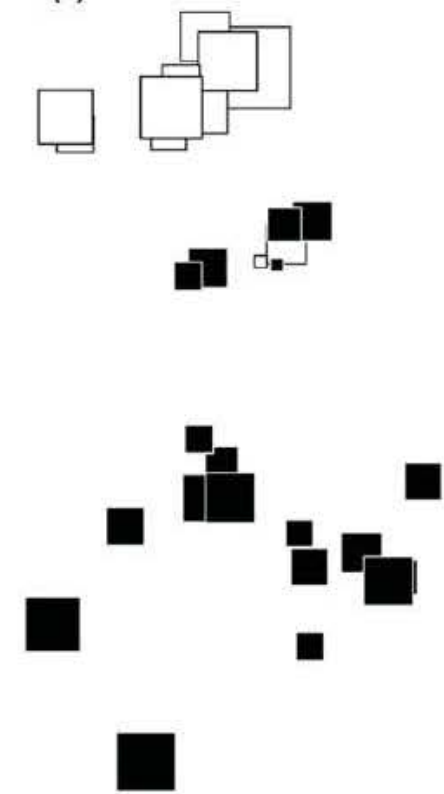

(d)

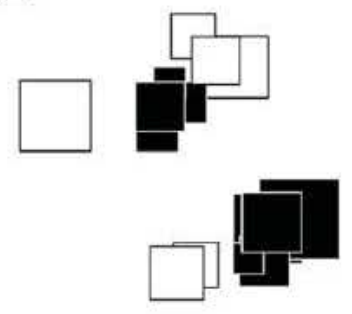

(e)

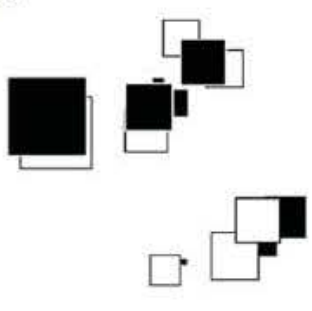

Figure 2 Connection network based on geography (latitude plus longitude) of 31 burrowing parrot (Cyanoliseus patagonus) localities in southern South America that were sampled for genetic analysis. (a) Connection network for which the distribution of genetic variation was significantly autocorrelated superimposed onto a map, (b) bar plots showing each component ordered by eigenvalue, and (c e) plots of the three components with highest positive eigenvalues after spatial principal component analysis (sPCA). The sPC scores may be either positive (black squares) or negative (white squares) and their absolute value is proportional to the size of the plotted square. Therefore, smaller squares indicate a value of the score close to zero while bigger squares denote values further from zero (i.e. more positive or negative). For plots showing the eigenvalue of each component ( $y$ axis) and the amount of genetic variance it described ( $x$ axis) see Appendix S2. Locality numbers and landscapes are as in Table 2. For geographical names and coordinates see Fig. 1.

Colonies are colour coded according to the landscapes where they are located: blue for Patagonia, green for the Pampas, red for the Serranías Centrales of Argentina (hills of San Luis and Córdoba), light brown for the lowlands of Cuyo, yellow for the Precordillera (pre Andes), and black for the Chilean Matorral. 

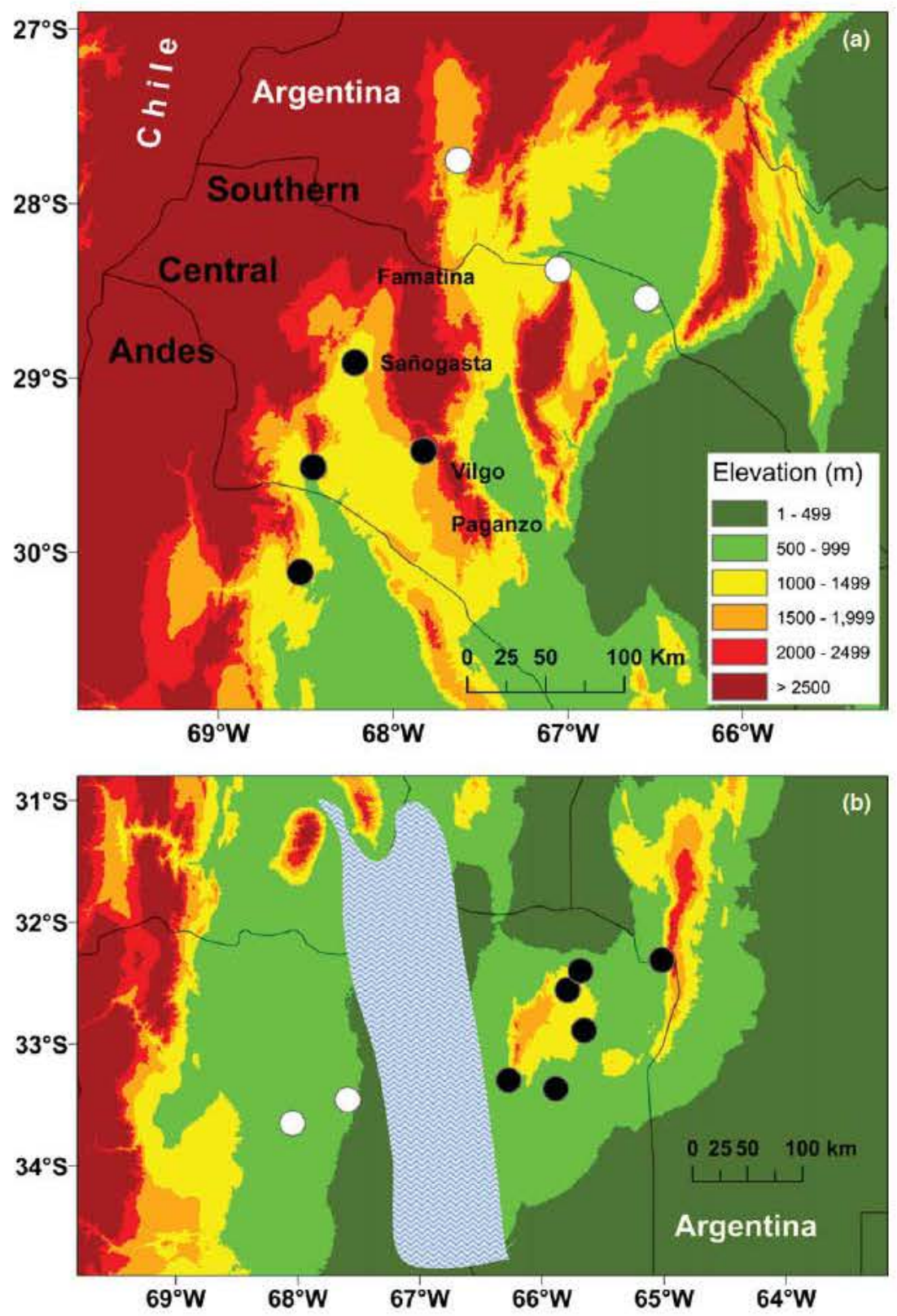

Figure 3 The sierras of Famatina, Sañogasta and Paganzo (up to $5000 \mathrm{~m}$ ) separate two populations of the burrowing parrot (Cyanoliseus patagonus) distributed in different intermontane basins (a). The Sierras de San Luis and the Sierra de Comechingones, the approximate location of a large ancient lake that occupied the region shortly after Last Glacial Maximum (Vuilleumier, 1971), and two groups of genetically distinct burrowing parrot populations are shown in panel (b).

PPC 2, PPC 4 and PPC 5 and are most genetically differenti ated from Patagonian colonies because their squares are the same colour as the other Andean colonies but consistently larger (Figs S3c, S4c \& S5c).

\section{DISCUSSION}

Modification of sPCA, a method originally developed for spa tial genetics (Jombart et al., 2008), allowed us to investigate the interplay of geographical and climate heterogeneity in the structuring of burrowing parrot populations on a continental scale. Despite limited genetic data, we were able to explicitly disentangle genetic patterns related to geography and climate (Fig. 2, Figs S2 S5). Geographically, sPCA revealed previously undetected conservation relevant genetic structure, whereas climatically, temperature and precipitation variables were not similarly related to geography. As predicted, we discovered a less prominent role of temperature based variables and a more important role for precipitation, although this resulted more from dissection of genetic and climatic variation via SPCA than from accounting for regressional redundancy. Differences in precipitation helped reveal cryptic climatic affinities between the areas and SPCA showed that precipitation played a key role in the structuring of burrowing parrot diversity. 


\section{Spatial landscape}

Geographically, sPCA divided the species distribution into two main areas, Patagonia and the pre Andes, which were connected by an area of geographical transition represented by eight localities (Fig. 2c). This result is in line with a previ ous study based on mtDNA (Masello et al., 2011). But, by using sPCA, we were able to reveal previously undetected conservation relevant genetic structure: the pre Andean pop ulations and the eight transition localities were each divided into two groups (Fig. 2d).

The two pre Andean groups corresponded to populations distributed in two different intermontane basins separated by the sierras of Famatina, Sañogasta, Vilgo and Paganzo (up to $5000 \mathrm{~m}$; Fig. 3a). Importantly, all but one of the colonies in these two groups were located on the slopes of the sierras. This is because of (1) the availability of high vertical cliffs needed to dig nests, and (2) the greater precipitation of the slopes comparing with lower areas of the basins (Strecker et al., 2007).

In the area of geographical transition (Serranías Centrales), six of the transition localities $(6,25,26,27,28$ and 29) formed a genetically homogeneous group (Fig. 2d) located between the ridges Sierra de San Luis (up to $1900 \mathrm{~m}$ ) and Sierra de Comechingones (up to $2300 \mathrm{~m}$; Fig 3b). Further west, the two transition localities in the lowlands of Cuyo $(13,14)$ formed another genetically homogeneous group (Fig. 2d). These two colonies are located on what would today be the other side of a large ancient lake that existed shortly after the Last Glaciation Maximum (Fig. 3b; Vuilleu mier, 1971) and their genetic uniqueness may be the out come of barriers that are no longer evident in the landscape (e.g. Lougheed et al., 1999). Estimates of divergence times between the Cuyo and the Serranías Centrales populations would be needed to test this hypothesis with the expectation that divergence dates to the end of the Last Glacial Maxi mum. Alternatively, the observed structuring could arise from other scenarios, such as the precipitation differences between localities (Figs S3c, S4c \& S5c).

Apart from revealing important management units, the previously undetected genetic structure visualized through the use of sPCA further demonstrates the crucial role of the Andes, the pre Andes and associated ridges in shaping the genetic structure of animal populations in South America. Although, trans Andean dispersal has been found in several organisms, including the burrowing parrot (Masello et al., 2011), the Andes, the pre Andes and associated ridges consti tute orographic structures that may impose constraints to gene flow for several taxa examined to date (e.g. Turchetto Zolet et al., 2013).

\section{Climatic landscape}

When temperature based variables were considered, tempera ture seasonality accounted for almost all of the variance among the data, showing a nonlinear relationship with both the geographical coordinates and microsatellite allele fre quency distribution. So, despite the higher prediction power of temperature based variables, their influence on the distri bution of the genetic variation is less straightforward to interpret. This is because (1) temperature varies most widely on either side of the Andes, as do microsatellite allele fre quencies separating Chilean C. p. bloxami from all other populations, and (2) on the Argentinian side of the Andes, temperature ranges for geographically distinct Patagonia, the Serranías Centrales and the pre Andes are largely overlap ping. This suggests that while large variation in temperature and genetics are apparent on either side of the Andes, tem perature did not play a key role in the structuring of bur rowing parrot diversity in Argentina.

In the case of precipitation, annual precipitation was the main contributor, followed by precipitation of the coldest quarter and precipitation of the warmest quarter. Interest ingly, only the pairs of PCs that contained PPC 3, mainly explained by the precipitation of the wettest quarter, showed significant patterns (Fig. 2, Figs S2 S5). In the case of the Chilean and Patagonian populations the precipitation of the wettest quarter corresponds to the winter months, while in the case of the pre Andes and Cuyo populations corresponds to spring to early summer (Hajek \& di Castri, 1975; Paruelo et al., 1998). Altogether, by taking into account the redun dancy among climatic variables, sPCA revealed a more cryp tic and important role of precipitation than previously observed (Masello et al., 2011). These results can be properly understood by considering crucial aspects of the ecology and the breeding biology of the burrowing parrot. Burrowing parrots are mainly distributed in dry landscapes (Masello et al., 2011; Fig. 1) but are never found far from water as they need to drink several times daily (Masello et al., 2011). Both the amount of precipitation during the breeding season (spring to early summer) and the amount of precipitation during the months before the breeding season (winter) are directly linked to breeding success, and hence fitness, of the burrowing parrots in north eastern Patagonia (Masello \& Quillfeldt, 2004). In years of reduced rain caused by the La Niña phase of the El Niño Southern Oscillation (ENSO), the breeding success of the parrots was negatively affected by strongly reduced primary productivity and food availability (Masello \& Quillfeldt, 2004). The strong species wide depen dence on the presence of water, coupled with heterogeneous regional levels of precipitation across the study area, may have led to local adaptation to differential precipitation regimes, which could then influence the distribution of genetic variation by limiting gene flow to precipitation simi lar areas.

Precipitation based connection networks and genetic scores also separated Patagonian from pre Andean regions, and populations on either side of the Andes in Chile and Argentina. In all sPCA results (geography, temperature and precipitation) colonies in the Serranías Centrales and in the lowlands of Cuyo are intermediate between the pre Andean and Patagonian populations (Fig. 2c, Figs S2 S5). Moreover, 
the precipitation based connection networks and genetic scores clearly grouped populations in the Serranías Centrales with pre Andean localities and confirmed the climatically intermediate position of the Cuyan populations. This adds to previous evidence of a stable hybrid zone that has been func tioning as a channel for genetic exchange between Patago nian and Andean populations for several thousand years (Masello et al., 2011). Expanding Patagonian individuals into the south eastern range of the Andinus population thus resulted in the evolution of an intermediate phenotype: C. $p$. conlara (Nores \& Yzurieta, 1983). These results also corrobo rate evidence that suggests a potential role for climatically intermediate regions in structuring stable hybrid zones. Stud ied taxa ranging from trees (e.g. Cullingham et al., 2012; Gérard et al., 2013) to invertebrates (e.g. Hilbish et al., 2012) and vertebrates (e.g. Espregueira Themudo et al., 2012) revealed precipitation and temperature to be among the main variables associated with the position of hybrid zones. This highlights the necessity of investigating the role of cli mate in the origin and evolution of hybrid zones.

\section{The utility of SPCA in dissecting geographical and climatic landscapes}

This study uses multivariate sPCA and explores its usefulness in landscape genetic studies. This is because landscape stud ies cannot be limited to just understanding correlations between genetic and physical distances, but also extended to correlations between genetic and the multidimensional eco logical niches in which species evolve. This perspective could be further extended by carrying out long term population genetic studies, based on explicit working hypotheses that compare different evolutionary scenarios while considering ecological niche complexity. Here, we used a model free multivariate approach (PCA) to reduce the multivariate space described by climatic variables in order to analyse them within a sPCA framework. We acknowledge that such application may not be ideal in summarizing climatic infor mation and may lead to some redundancy in dissecting the contribution of each variable to the climatic landscape. How ever, in the absence of explicit ecological indices that would enable the ordering of entities according to climatic differ ences, PCA seems a natural statistical solution given its abil ity to reduce a variable's correlation and provide ordered reciprocal coordinates without specific assumptions. A com parison of the results from geographical and precipitation based variables showed that geography cannot be regarded as simple straight line physical distances. Geography is also important because of its interplay with climate and the cli matic differences it implies. Most interestingly, differences in seasonal precipitation helped reveal cryptic climatic affinities between the area of geographical transition and the pre An dean localities. These climatic parameters also separate quite clearly the Patagonia region and the pre Andean colonies, thereby explaining the differences that would be expected among different habitats.
These novel climatic inferences, intractable through stan dard climate genetic regressions, highlight the importance of our modified sPCA approach in revealing how identifiable climatic variables can drive statistically significant, but often cryptic, genetic patterns across climatic landscape space. This method could potentially be applied to any species distrib uted over a climatically heterogeneous landscape.

\section{Conservation implications}

Burrowing parrots currently face a precarious conservation situation owing to: (1) the low population sizes of Bloxami (approximately 6000 individuals) and Andinus (2000 nests) mtDNA haplogroups; (2) the low population size in the hybrid zone of the Serranías Centrales (1700 individuals); (3) the strong reduction (46\%) in population size of Patagonus1 and Patagonus 2 during the last 30 years, following the severe reduction in size of the formerly largest known colony of some 50,000 nests today reduced to a few hundred nests; and (4) the concentration of $79 \%$ of all Patagonus1 and Pat agonus $2 \mathrm{mtDNA}$ haplogroups (i.e. $71 \%$ of the total species population) in just one colony, namely El Cóndor (e.g. Voi tzuk, 1975; Rojas Martínez, 2008; Masello \& Quillfeldt, 2012; for haplogroups see Masello et al., 2011). Previously, Masello et al. (2011) identified four different management units, cor responding to the populations in Chile, the lowlands of Cuyo, Patagonia, and the Serranías Centrales. However in this study, sPCA revealed hitherto undetected genetic struc turing (Fig. 2, Figs S3 S5) based on geography, both for the lowlands of Cuyo and the Serranías Centrales (Fig. 2d). The two genetically distinct subunits detected in the lowlands of Cuyo correspond to colonies separated by huge ridges and distributed in different intermontane basins (Fig. 3a). sPCA based on precipitation also clearly dissected two genetically distinct subunits in the Serranías Centrales (Figs S3c, S4c \& $\mathrm{S} 5 \mathrm{c})$. Thus, with the aid of sPCA, we now consider six dis tinct management units for conservation across the species' range. This highlights the further usefulness of geographical and climatic sPCA in detecting discontinuities in genetic het erogeneity, as it has improved our ability in identifying man agement units for conservation across continental scale terrestrial ecosystems.

\section{ACKNOWLEDGEMENTS}

We thank Orlando Amaya, Brent Barrett, Julio Bufelli, Mirta Carbajal, Gabriel Cortéz, Maritza Cortés, Francesca Cunninghame, Miguel Escobar, Mauricio Failla, Esteban Fernández, Víctor Fratto, Pablo Giovine, Patricia González, Guillermo Luna Jorquera, Mariano Linares, Fabián Llanos, Walter Marcial, Gabriela Murga Velasco, Juanjo Navarro, Sandra Rivera, Sergio Sánchez, Lorenzo Sympson, Adalberto Taux, Ricardo Torres and Luis Valenzuela Riquelme for helping with sample collection, and Gernot Segelbacher and Nadine Klauke for the development of the microsatellite loci. This project was supported by: World Parrot Trust, Deutsche 
Ornithologen Gesellschaft, Liz Claiborne Art Ortenberg Foundation, and Wildlife Conservation Society. We thank Ann Michels for helping with the application for permits in Chile. In Argentina, this study was carried out under permis sion of the Dirección de Fauna de Río Negro (143089 DF 98), and the Secretaría de Ambiente de la Nación.

\section{REFERENCES}

Bucher, E.H., Bertin, M.A. \& Santamaria, A.B. (1987) Repro duction and molt in the burrowing parrot. Wilson Bulletin, 99, 107109.

Buckley, J., Butlin, R.K. \& Bridle, J.R. (2012) Evidence for evolutionary change associated with the recent range expansion of the British butterfly, Aricia agestis, in response to climate change. Molecular Ecology, 21, 267 280.

Cullingham, C.I., James, P.M.A., Cooke, J.E.K. \& Coltman, D.W. (2012) Characterizing the physical and genetic struc ture of the lodgepole pine $\times$ jack pine hybrid zone: mosaic structure and differential introgression. Evolution ary Applications, 5, 879891.

Darrieu, C.A. (1980) Las razas geográficas de Cyanoliseus patagonus (Aves: Psittacidae). Neotropica, 26, 207216.

Eckert, A.J., Bower, A.D., González Martínez, S.C., Wegrzyn, J.L., Coop, G. \& Neale, D.B. (2010) Back to nature: eco logical genomics of loblolly pine (Pinus taeda, Pinaceae). Molecular Ecology, 19, 37893805.

Espregueira Themudo, G., Nieman, A.M. \& Arntzen, J.W. (2012) Is dispersal guided by the environment? A compar ison of interspecific gene flow estimates among differenti ated regions of a newt hybrid zone. Molecular Ecology, 21, 53245335.

Gérard, P.R., Temunović, M., Sannier, J., Bertolino, P., Dufour, J., Frascaria Lacoste, N. \& Fernández Manjarrés, J.F. (2013) Chilled but not frosty: understanding the role of climate in the hybridization between the Mediterranean Fraxinus angustifolia Vahl and the temperate Fraxinus excelsior L. (Oleaceae) ash trees. Journal of Biogeography, 40, 835846.

Goudet, J. (1995) FSTAT (version 1.2): a computer program to calculate F statistics. Journal of Heredity, 86, 485486.

Hajek, E. \& di Castri, F. (1975) Bioclimatografía de Chile. Di rección de Investigación, Universidad Católica de Chile, Santiago.

Hijmans, R.J., Cameron, S.E., Parra, J.L., Jones, P.G. \& Jarvis, A. (2005) Very high resolution interpolated climate sur faces for global land areas. International Journal of Clima tology, 25, 19651978.

Hilbish, T.J., Lima, F.P., Brannock, P.M., Fly, E.K., Rognstad, R.L. \& Wethey, D.S. (2012) Change and stasis in marine hybrid zones in response to climate warming. Journal of Biogeography, 39, 676687.

Holderegger, R. \& Wagner, H.H. (2006) A brief guide to landscape genetics. Landscape Ecology, 21, 793796.
Iglesias, A., Artabe, A.E. \& Morel, E.M. (2011) The evolution of Patagonian climate and vegetation from the Mesozoic to the present. Biological Journal of the Linnean Society, 103, 409422.

Jombart, T. (2008) adegenet: a R package for the multivariate analysis of genetic markers. Bioinformatics, 24, 14031405.

Jombart, T., Devillard, S., Dufour, A.B. \& Pontier, D. (2008) Revealing cryptic spatial patterns in genetic variability by a new multivariate method. Heredity, 101, 92103.

Klauke, N., Masello, J.F., Quillfeldt, P. \& Segelbacher, G. (2009) Isolation of tetranucleotide microsatellite loci in the burrowing parrot (Cyanoliseus patagonus). Journal of Ornithology, 150, 921924.

Kottek, M., Grieser, J., Beck, C., Rudolf, B. \& Rubel, F. (2006) World map of the Köppen Geiger climate classifi cation updated. Meteorologische Zeitschrift, 15, 259264.

Lougheed, S.C., Gascon, C., Jones, D.A., Bogart, J.P. \& Boag, P.T. (1999) Ridges and rivers: a test of competing hypoth eses of Amazonian diversification using a dart poison frog (Epipedobates femoralis). Proceedings of the Royal Society B: Biological Sciences, 266, 18291835.

Manel, S., Schwartz, M.K., Luikart, G. \& Taberlet, P. (2003) Landscape genetics: combining landscape ecology and population genetics. Trends in Ecology and Evolution, 18, 189197.

Manel, S., Poncet, B.N., Legendre, P., Gugerli, F. \& Holderegger, R. (2010) Common factors drive adaptive genetic variation at different spatial scales in Arabis alpina. Molecular Ecology, 19, 38243835.

Masello, J.F. \& Quillfeldt, P. (2004) Consequences of La Niña phase of ENSO for the survival and growth of nestling burrowing parrots on the Atlantic coast of South America. Emu, 104, 337346.

Masello, J.F. \& Quillfeldt, P. (2012) ¿Cómo reproducirse exi tosamente en un ambiente cambiante? Biología reproducti va de los loros barranqueros Cyanoliseus patagonus en el nordeste de la Patagonia. Hornero, 27, 7388.

Masello, J.F., Pagnossin, M.L., Sommer, C. \& Quillfeldt, P. (2006) Population size, provisioning frequency, flock size and foraging range at the largest known colony of Psittaci formes: the burrowing parrots of the north eastern Patago nian coastal cliffs. Emu, 106, 6979.

Masello, J.F., Lubjuhn, T. \& Quillfeldt, P. (2008) Is the struc tural and psittacofulvin based colouration of wild burrow ing parrots Cyanoliseus patagonus condition dependent? Journal of Avian Biology, 39, 653662.

Masello, J.F., Quillfeldt, P., Munimanda, G.K., Klauke, N., Segelbacher, G., Schaefer, H.M., Failla, M., Cortés, M. \& Moodley, Y. (2011) The high Andes, gene flow and a stable hybrid zone shape the genetic structure of a wide ranging South American parrot. Frontiers in Zoology, 8, 16.

Moran, P.A.P. (1950) Notes on continuous stochastic phenomena. Biometrika, 37, 1723.

Nores, M. \& Yzurieta, D. (1983) Especiación en las Sierras Pampeanas de Córdoba y San Luis (Argentina), con 
descripción de siete nuevas subespecies de aves. Hornero (ext.), 12, 88102.

Oksanen, J., Blanchet, F.G., Kindt, R., Legendre, P., Minchin, P.R., O'Hara, R., Simpson, G.L., Solymos, P., Stevens, M. \& Wagner, H. (2012) vegan: community ecology package. $\mathrm{R}$ package version 2.0 2. R Foundation for Statistical Com puting, Vienna.

Paruelo, J.M., Beltrán, A.B., Jobbágy, E.G., Sala, O.E. \& Golluscio, R.A. (1998) The climate of Patagonia: general patterns controls on biotic processes. Ecología Austral, 8, 85101.

Peel, M.C., Finlayson, B.L. \& McMahon, T.A. (2007) Updated world map of the Köppen Geiger climate classifi cation. Hydrology and Earth System Sciences Discussions, 11, 16331644.

R Core Team(2013) $R$ : a language and environment for statis tical computing. R Foundation for Statistical Computing, Vienna.

Reuter, H.I., Nelson, A. \& Jarvis, A. (2007) An evaluation of void filling interpolation methods for SRTM data. Interna tional Journal of Geographical Information Science, 21, 983 1008 .

Rojas Martínez, M.E. (2008) Estudio de la interacción entre las poblaciones de loro tricahue Cyanoliseus patagonus blox ami, y la actividad agrícola en las comunas de Vicuña y Monte Patria, Región de Coquimbo, Chile. Servicio Agrícola y Ganadero, Santiago de Chile.

Ruzzante, D.E. \& Rabassa, J. (2011) Palaeogeography and palaeoclimatology of Patagonia: effects on biodiversity. Biological Journal of the Linnean Society, 103, 221228.

Sérsic, A.N., Cosacov, A., Cocucci, A.A., Johnson, L.A., Poz ner, R., Avila, L.J., Sites, J.W., Jr \& Morando, M. (2011) Emerging phylogeographical patterns of plants and terres trial vertebrates from Patagonia. Biological Journal of the Linnean Society, 103, 475494.

Sork, V.L. \& Waits, L. (2010) Contributions of landscape genetics approaches, insights, and future potential. Molecular Ecology, 19, 34893495.

Sork, V.L., Davis, F.W., Westfall, R., Flint, A., Ikegami, M., Wang, H. \& Grivet, D. (2010) Gene movement and genetic association with regional climate gradients in Cali fornia valley oak (Quercus lobata Née) in the face of cli mate change. Molecular Ecology, 19, 38063823.

Strecker, M.R., Alonso, R.N., Bookhagen, B., Carrapa, B., Hilley, G.E., Sobel, E.R. \& Trauth, M.H. (2007) Tectonics and climate of the southern central Andes. Annual Review of Earth and Planetary Sciences, 35, 747787.

Tambussi, C.P. (2011) Palaeoenvironmental and faunal infer ences based on the avian fossil record of Patagonia and Pampa: what works and what does not. Biological Journal of the Linnean Society, 103, 458474.

Ter Braak, C.J. (1986) Canonical correspondence analysis: a new eigenvector technique for multivariate direct gradient analysis. Ecology, 67, 11671179.
Turchetto Zolet, A., Pinheiro, F., Salgueiro, F. \& Palma Silva, C. (2013) Phylogeographical patterns shed light on evolu tionary process in South America. Molecular Ecology, 22, 11931213.

Voitzuk, L. (1975) El loro barranquero, plaga agrícola del sud de la provincia de Buenos Aires. Boletín Fitosanitario, 48, 3134 .

Vuilleumier, B.S. (1971) Pleistocene changes in the flora and fauna of South America. Science, 173, 771780.

van den Wollenberg, A.L. (1977) Redundancy analysis an alternative for canonical correlation analysis. Psychometrika, 42, 207219 .

Appendix S1 Supplementary tables, including microsatellite genotypes from each sampled locality (Table S1), climatic parameters for localities with burrowing parrot colonies (Table S2), and the correlation matrix for the geographical and climatic variables (Table S3).

Appendix S2 Supplementary figures, including a plot of the matrix of correlations for geography and the climatic vari ables (Fig. S1), connection networks and plots of tempera ture and precipitation components (Figs S2 S5), eigenvalues of each component and the amount of genetic variance described (Figs S6 S10).

\section{BIOSKETCH}

Juan F. Masello is a research scientist at the Justus Liebig Universität Gießen (Germany). The primary focus of his research has been (1) the responses of individuals to chang ing environmental conditions, (2) reproductive strategies, (3) individual reproductive performance, (4) foraging strategies, and (5), more recently, population genetics. Masello's research has been conducted primarily on wild populations of parrots, penguins, gulls and cormorants, as these offer excellent opportunities for testing a number of theoretical predictions. Since 1998, he has coordinated the Burrowing Parrot Project. Since 2013, he has been Chair of the Research Coordination Committee on Parrots (RCCP) of the Interna tional Ornithologists' Union (IOU).

Author contributions: J.F.M., P.Q., M.W. and Y.M. con ceived the study. J.F.M. and P.Q. carried out the fieldwork. S.N. generated part of the data. V.M. and Y.M. carried out bioinformatic analyses. V.M., Y.M., J.F.M. and P.Q. were responsible for data analysis and drafted the manuscript. All authors reviewed the final draft of the manuscript. 